\title{
ARTICLE \\ Effect of Varying Aerosol Concentrations and Relative Humidity on Visibility and Particle Size Distribution in Urban Atmosphere
}

\author{
Ummulkhair Abdulkarim $^{1^{*}}$ Bello Tijjani $^{2}$ \\ 1. Department of Physics, Sa'adatu Rimi College of Education Kano, P. M. B. 3218, Kano State, Nigeria \\ 2. Department of Physics, Bayero University Kano, P.M.B. 3011, Kano State, Nigeria
}

\section{ARTICLE INFO}

Article history

Received: 4 July 2021

Accepted: 28 July 2021

Published Online: 12 August 2021

Keywords:

Aerosol concentration

Humidification factor

Hygroscopic growth

Particle size distribution

Visibility enhancement

\begin{abstract}
Atmospheric aerosol concentrations have been found to change constantly due to the influence of source, winds and human activities over short time periods. This has proved to be a constraint to the study of varied aerosol concentrations in urban atmosphere alongside changing relative humidity and how it affects visibility and aerosol particle size distribution. In this research simulation was carried out using Optical Properties of Aerosols and Clouds (OPAC 4.0) average concentration setup for relative humidity (RH) $0-99 \%$ at visible wavelength $0.4-0.8 \mu \mathrm{m}$ to vary the concentrations of three aerosol components: WASO (Water-soluble), INSO (Insoluble) and SOOT. The Angstrom exponents $(\alpha)$, the curvatures $\left(\alpha_{2}\right)$ and atmospheric turbidities $(\beta)$ were obtained from the regression analysis of Kaufman's first and second order polynomial equations for visibility. The research determined the mean exponent of the aerosol size growth curve $(\mu)$ from the effective hygroscopic growth $\left(\mathrm{g}_{\text {eff }}\right)$ and the humidification factors $(\gamma)$ from visibility enhancement $\mathrm{f}(\mathrm{RH}, \lambda)$. The mean exponent of aerosol size distributions (v) was determined from $\mu$ and $\gamma$. The results showed that with varied WASO, INSO and SOOT concentrations respectively at different $\mathrm{RH}$, aerosol particle size distributions showed bimodal characteristics with dominance of fine mode particles. Hazy atmospheric conditions prevailed with increasing turbidity.
\end{abstract}

particles known as aerosols in the atmosphere. Because of their differences in chemical and physical components, aerosol particles have the ability to absorb more water compared to their dry state as atmospheric moisture increases. This changes their optical properties as they increase in size ${ }^{[11]}$. Aerosols within urban atmosphere can be composed of water-soluble aerosols from industrial emissions, insoluble and soot from biomass and biofuel emissions respectively ${ }^{[3]}$. Emissions from human activities such as vehicular emissions are the major source of pollution and aerosols. Biomass burning and dust

*Corresponding Author:

Ummulkhair Abdulkarim,

Department of Physics, Sa'adatu Rimi College of Education Kano, P. M. B. 3218, Kano State, Nigeria;

Email: gjummu.physicist@yahoo.com 
transported from dry desert areas surrounding an urban atmosphere ${ }^{[4]}$ and nearby regions can also contribute to aerosol characteristics which alter their optical properties ${ }^{[3]}$. Often, aerosols undergo coagulation and become mixed internally and component-wise, ${ }^{[10]}$ even the presence of water soluble aerosols wrapped around insoluble aerosol cores can encourage hygroscopic properties ${ }^{[11-14]}$.

Investigations have been carried out by many studies using laboratory generated aerosols to understand how water soluble and insoluble aerosols respond to atmospheric moisture. These experimental methods investigated the effects of relative humidity on the ability of aerosols to scatter visible light and how these scattering effects are applicable to an urban atmosphere ${ }^{[12-18]}$. Aerosols are very diverse and constantly changing in their form, shape, size and concentrations globally, this makes them difficult to study. Their constant changing nature also causes gaps in their coverage through time and space and these cause biases in data when collecting ground and satellite data. Most studies just focus on short time periods and although long-term investigations of aerosol optical properties are important, they are rarely reported in literature ${ }^{[19]}$. Because of unavoidable gaps and biases in data, the data collected with satellite, insitu and ground-based instruments could not be sufficient for a direct local assessment of the long-term aerosol effect in urban atmosphere ${ }^{[20]}$. Furthermore, more data and detailed studies on how aerosol mixing and varied concentration can affect aerosol hygroscopic growth is needed ${ }^{[21]}$, because present available data does not allow for the varying of atmospheric aerosol concentrations, the use of model methods and simulations is imperative.

In this research, aerosol concentrations of watersoluble (WASO), Insoluble (INSO) and SOOT were varied through external mixing to analyze the effect of relative humidity $(\mathrm{RH})$ and varying aerosol concentrations on visibility and particle size distribution in urban atmosphere. From the extinction coefficients extracted, visibilities and visibility enhancement factors were determined and effective hygroscopic growth were also determined using aerosol particle radii.

\section{Theoretical Framework}

Visibility calculations are carried out based on the Koschmieder formula using extracted extinction coefficients for particular relative humidity at corresponding visible spectral wavelength ${ }^{[12]}$.

$V_{\text {Vis }}(\lambda)=\frac{3.912}{\sigma_{\text {ext }}(\lambda)}$

But extinction coefficient is defined in terms of wavelength using the inverse power law as ${ }^{[22]}$;

$\sigma_{\text {ext }}(\lambda)=\beta \lambda^{-\alpha}$
$V_{V i s}(\lambda)=\frac{3.912}{\beta} \lambda^{\alpha}$

Such that ${ }^{[23]}$ Equation (1) and Equation (2) give the expression in Equation (4);

$\ln \left(\frac{V_{V i s}(\lambda)}{3.912}\right)=\alpha \ln (\lambda)-\ln (\beta)$

Performing a regression analysis on Kasten's (1969) representation of Equation (1) gives $\alpha$ (Angstrom exponent) and $\beta$ (turbidity) ${ }^{[12,24]}$. An empirical relationship between visibility and wavelength can then be obtained with a $2^{\text {nd }}$-order polynomial ${ }^{[25-27]}$.

$\ln \left(\frac{V_{V i s}(\lambda)}{3.912}\right)=\alpha_{1}(\ln (\lambda))+\alpha_{2}(\ln (\lambda))^{2}-\ln (\beta)$

Where $\alpha_{2}$ indicates aerosol particle size ${ }^{[28]},-\alpha_{2}$ means fine mode particle dominance and $+\alpha_{2}$ coarse mode particle dominance ${ }^{[24,29]}$.

The Visibility Enhancement which gives the relationship between visibility and relative humidity is presented in Equation (6) ${ }^{[30-31]}$.

$f(R H, \lambda)=\frac{V_{V i s}(R H, \lambda)}{V_{V i s}\left(R H_{0}, \lambda\right)}=\left[\frac{1-R H}{1-\left(R H_{0}\right)}\right]^{-\gamma}$

To be considered for regression analysis Equation (6) takes the form;

$\ln \left(\frac{V_{V i s}(R H, \lambda)}{V_{V i s}\left(R H_{0}, \lambda\right)}\right)=-\gamma \ln (1-R H)$

Where $R H_{0}=0 \%$ and $V_{\text {Vis }}(R H, \lambda)$ is the visibility at wavelength $\lambda$ at any given relative humidity (RH). $\gamma$ can be expressed as ${ }^{[27]}$;

$\mu \gamma=v-1$

Where $\gamma$ shows the dependence of visibility on relative humidity $(\mathrm{RH})$ resulting from the change in the particle size of the aerosol particles upon humidification ${ }^{[32]} . \mu$ is the mean exponent aerosol growth curve ${ }^{[33]}$ while $v$ is the mean exponent aerosol size distribution presented in the Junge power law size distribution function;

$\frac{d n(r)}{d(\log r)}=c r^{-v}$

with c as a constant and $d n(r)$ representing number of particles with radii between $\mathrm{r}$ and $r+d r^{[33]}$.

The hygroscopic growth $g(R H)$ experienced by a single particle according to ${ }^{[34]}$ is given by;

$$
g(R H)=\frac{r(R H)}{r\left(R H_{0}\right)}
$$

with $r(R H)$ being the radius at a given relative humidity $\mathrm{RH}$ and $r\left(\mathrm{RH}_{0}\right)$ representing the radius at $0 \%$ relative humidity. For different aerosols of different components Equation (10) takes the form of Equation (11) which is the effective hygroscopic growth of the whole aerosol population; 


$$
g_{e f f}(R H)=\left(\sum_{k} x_{k} g_{k}^{3}(R H)\right)^{\frac{1}{3}}
$$

where $x_{\mathrm{k}}$ is the volume mix ratio of the $\mathrm{k}^{\text {th }}$ term and $g_{k}$ is the hygroscopic growth of the $\mathrm{k}^{\text {th }}$ component ${ }^{[32]}$. The relationship between effective growth and relative humidity (RH) is expressed as ${ }^{[34]}$;

$g_{e f f}(R H)=\left[\frac{1-(R H)}{1-\left(R H_{0}\right)}\right]^{-\frac{1}{\mu}}$

where $\mu$ is the mean exponent of the aerosol growth curve as defined in Equation (8). Equation (12) can be written as Equation (13) for regression analysis purposes;

$$
\ln g_{\text {eff }}(R H)=-\frac{1}{\mu} \ln (1-R H)
$$

Using Equation (8), the mean exponent of the aerosol size distribution (v) can be expressed Equation (14) in terms of $\mu$ and $\gamma$.

$v=\mu \gamma+1$

\section{Method}

\subsection{OPAC Implementation}

The method employed in this research is a simulation carried out using the software package Optical Properties of Aerosols and Clouds (OPAC 4.0). The first part of OPAC is a dataset of microphysical properties which gives results on aerosol components at different wavelengths for different relative humidities. FORTRAN is the second part of the program from which the user can extract data from the above mentioned datasets for calculation of optical properties of mixtures of stored aerosol components. This work used three aerosol components representing the urban environment and varied the components to obtain five models each. The three components considered were WASO (water-soluble), INSO (insoluble) and SOOT.

To vary component mixtures for WASO, selection was made for component number density such that WASO aerosol concentration is varied at constant INSO and SOOT aerosol concentration. For INSO, selection was made for component number density such that INSO aerosol concentration is varied at constant WASO and SOOT aerosol concentration while for SOOT, selection was made for component number density such that SOOT aerosol concentration is varied at constant INSO and WASO aerosol concentrations. The input for height profile designated for urban aerosols was selected to give the aerosol mixing layer (layer above ground and Top of atmosphere) for the distribution of aerosol particles with height as suggested by Hess, Koepke and Schult (1998) ${ }^{[35]}$. Only wavelengths belonging to aerosols at the visible spectral range were considered at eight relative humidities. The optical parameters of extinction coefficients, scattering coefficients and absorption coefficients were extracted.

\subsection{Data Analysis}

The extracted data from the OPAC simulation output files were used in the evaluation of the Angstrom coefficient $(\alpha)$, Curvature $\left(\alpha_{2}\right)$, Turbidity $(\beta)$, Mean exponent hygroscopic growth curve $(\mu)$, Mean exponent aerosol size distribution (v) and Humidification factor $(\gamma)$. Equation 1 was used for visibility calculations while a regression analysis was performed on Equation 4 to obtain $\alpha$ and $\beta$. From the regression analysis of the second order of the Kaufman's representation of the Koschmeider equation for atmospheric visibility (Equation 5), $\alpha_{2}$ is obtained. $\gamma$ and $\mu$ calculations are carried out using the inverse power law from Equation 6 and Equation 12 respectively while calculations for $v$ are carried out using Equation 7, Equation 13 and Equation 14.

\section{Results and Discussions}

In the simulation carried out, to vary component mixture concentrations, selection was made for number density such that for the WASO (water soluble) component mixture, number density takes values from $28,000.00$ $\mathrm{cm}^{3}$ to $29,000.00 \mathrm{~cm}^{3}$ through $200.00 \mathrm{~cm}^{3}$ increment at constant INSO and SOOT aerosol concentrations of $1.50 \mathrm{~cm}^{3}$ and $130,000.00 \mathrm{~cm}^{3}$ respectively. INSO aerosol number density had input values from $1.50 \mathrm{~cm}^{3}$ to 2.30 $\mathrm{cm}^{3}$ through $0.20 \mathrm{~cm}^{3}$ increment at constant WASO and SOOT aerosol concentrations of $28,000.00 \mathrm{~cm}^{3}$ and $130,000.00 \mathrm{~cm}^{3}$ respectively. SOOT aerosol number density however, had input values from $130,000.00 \mathrm{~cm}^{3}$ to $140,000.00 \mathrm{~cm}^{3}$ through $2,000 \mathrm{~cm}^{3}$ increment at constant WASO and INSO aerosol concentrations of $1.50 \mathrm{~cm}^{3}$ and $28,000.00 \mathrm{~cm}^{3}$ respectively. For the distribution of aerosol particles with height, the height profile designated for urban aerosols as suggested by Hess (1998) was selected to give the aerosol mixing layer with $\mathrm{H}_{\min }=2 \mathrm{Km}$ (layer above ground), $\mathrm{H}_{\max }=10 \mathrm{Km}$ (top of atmosphere) and $\mathrm{Z}=8 \mathrm{Km}$ (aerosol scale height). Only wavelengths belonging to aerosols were selected and these wavelengths were of the visible spectral wavelength of $0.4 \mu \mathrm{m}$ to 0.8 $\mu \mathrm{m}$ at eight relative humidities $(0 \%, 50 \%, 70 \%, 80 \%$, $90 \%, 95 \%, 98 \%$ and $99 \% \mathrm{RH})$. The maximum radius for mass calculation used was $7.5 \mu \mathrm{m}$ radius (only particles up to $7.5 \mu \mathrm{m}$ radius were considered). In this work, the Visibility Enhancement $f(R H, \lambda)$, analyzed at $\lambda=0.55$ $\mu \mathrm{m}, \lambda=0.65 \mu \mathrm{m}$ and $\lambda=0.75 \mu \mathrm{m}$. 


\subsection{Water-Soluble (WASO) Particle Concentration}

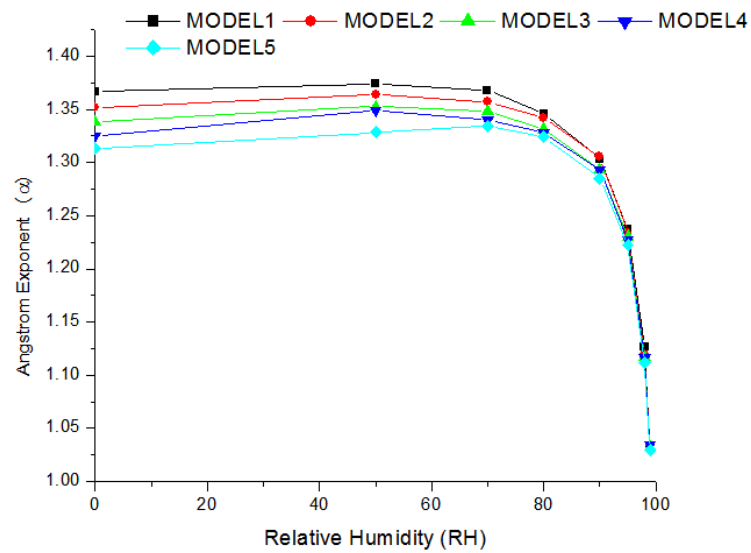

Figure 1. Graph of Angstrom Exponent $(\alpha)$ against Relative Humidity (RH) for five WASO Models

From Figure 1 at $0 \% \mathrm{RH}$ there is a very noticeable difference between $\alpha$ values of the five models. The values of $\alpha$ decrease from Model 1 to Model 5 such that with increasing WASO concentrations, there is an increase in fine mode particle distribution. $\alpha$ for each model is constant from $0-50 \% \mathrm{RH}$ and then decreases from 50 $100 \%$ RH. This indicates sedimentation of heavier particles from $50-99 \% \mathrm{RH}$ and saturation at $100 \% \mathrm{RH}$.

Table 1. Visibility analysis (Model 1- WASO)

\begin{tabular}{cccc|cccc}
\hline \multicolumn{4}{c|}{ Linear } & \multicolumn{4}{c}{ Quadratic } \\
\hline $\mathrm{RH}$ & $\mathrm{R}^{2}$ & $\alpha$ & $\beta$ & $\mathrm{R}^{2}$ & $\alpha_{1}$ & $\alpha_{2}$ & $\beta$ \\
\hline $0 \%$ & 0.99904 & 1.36649 & 0.08552 & 0.99994 & 1.59994 & 0.20704 & 0.08091 \\
$50 \%$ & 0.99835 & 1.37425 & 0.11476 & 0.99994 & 1.67971 & 0.27090 & 0.10673 \\
$70 \%$ & 0.99835 & 1.36823 & 0.13385 & 0.99994 & 1.71846 & 0.31060 & 0.12317 \\
$80 \%$ & 0.99835 & 1.34585 & 0.15620 & 0.99994 & 1.66395 & 0.28211 & 0.14484 \\
$90 \%$ & 0.99835 & 1.30340 & 0.21248 & 0.99994 & 1.66099 & 0.31713 & 0.19519 \\
$95 \%$ & 0.99641 & 1.23764 & 0.30775 & 0.99994 & 1.66011 & 0.37467 & 0.27840 \\
$98 \%$ & 0.99641 & 1.12685 & 0.52057 & 0.99994 & 1.55508 & 0.37978 & 0.47027 \\
$99 \%$ & 0.99405 & 1.03234 & 0.74748 & 0.99994 & 1.48430 & 0.40082 & 0.67146 \\
\hline
\end{tabular}

From Table 1 Model $1, \mathrm{R}^{2}$ values fit the equation models. From the linear part, the values of $\alpha$ are greater than 1 . This shows that the aerosols are fine mode particles. There is an increase in $\alpha$ value from $0-50 \%$ relative humidity and this is due to coagulation of particles at the onset of water uptake, these particles later drop from the atmosphere when they become too heavy. $\alpha$ values decrease from $50-99 \%$ relative humidity, this implies hygroscopic growth in aerosol particles and an increase in particle size distribution. From the quadratic part, $\alpha_{2}$ is positive which indicates a bimodal distribution and dominance of fine mode particles. The Turbidity $(\beta)$ is seen to increase from $0-99 \%$ relative humidity which indicates hazy atmospheric conditions and deterioration in visibility as relative humidity increases.

The variations in $\alpha, \alpha_{2}$ and $\beta$ in Models 2, 3, 4 and 5 are similar to those of Model 1 from Table 1 as seen from Appendix A Table 1, 3, 5, and 7 respectively.

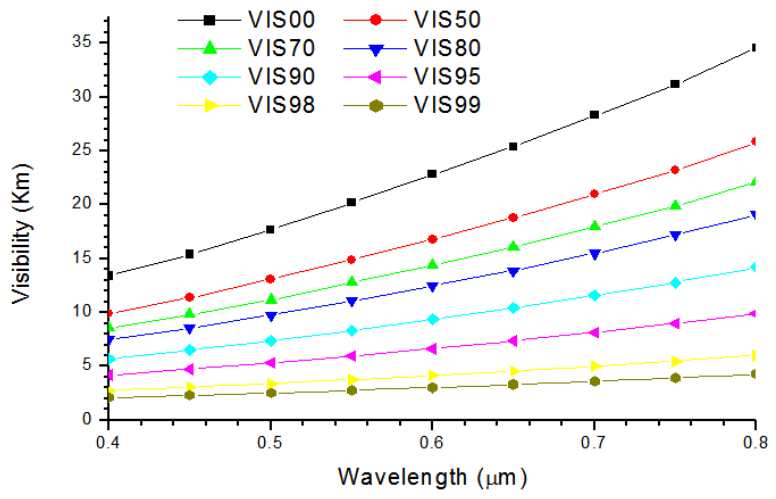

Figure 2. Visibility against Wavelength for WASO

From Figure 2, it can be seen that the visibility decreases with the increase in RH but increases with the increase in wavelength. There is a more noticeable decrease in visibility with increase in relative humidity $(\mathrm{RH})$ from $0 \%(\mathrm{RH})$ to $50 \%(\mathrm{RH})$ due to the onset of the intake of water by fine mode aerosol particles.

Table 2. Size Distribution and Hygroscopic Growth analysis (Model 1-WASO)

\begin{tabular}{cccc}
\hline & & & $\mu=5.12521$ \\
\hline$\lambda$ & $\mathrm{R}^{2}$ & $\gamma$ & $\nu$ \\
0.55 & 0.998 & 0.416 & 3.135338 \\
0.65 & 0.997 & 0.424 & 3.176105 \\
0.75 & 0.997 & 0.430 & 3.205313 \\
\hline
\end{tabular}

From Table 2 Model $1, \mathrm{R}^{2}$ values fit the equation models. The Visibility Enhancement $f(R H, \lambda)$ has satisfied the inverse power law. The increase in humidification factor $(\gamma)$ and the mean aerosol particle size distribution (v) with wavelength implies that the number of larger particles increases compared to the number of smaller particles at longer wavelengths and smaller particles have more effect in decreasing visibility at shorter wavelengths. The values of $v>3$ imply typical hazy atmospheric conditions (Junge 1958).

The variations in the humidification factor $(\gamma)$ and the mean aerosol particle size distribution ( $v$ ) of Models 2, 3, 4 and 5 are similar to those of Model 1 from Table 2 as seen in Appendix A Table 2, 4, 6 and 8 respectively.

The values of the mean exponent hygroscopic growth curve $(\mu)$ decreases with an increase in WASO aerosol concentration across the models and this implies an increase in the effective hygroscopic growth $\left(g_{e f f}\right)$. 


\subsection{Insoluble (INSO) Particle Concentration}

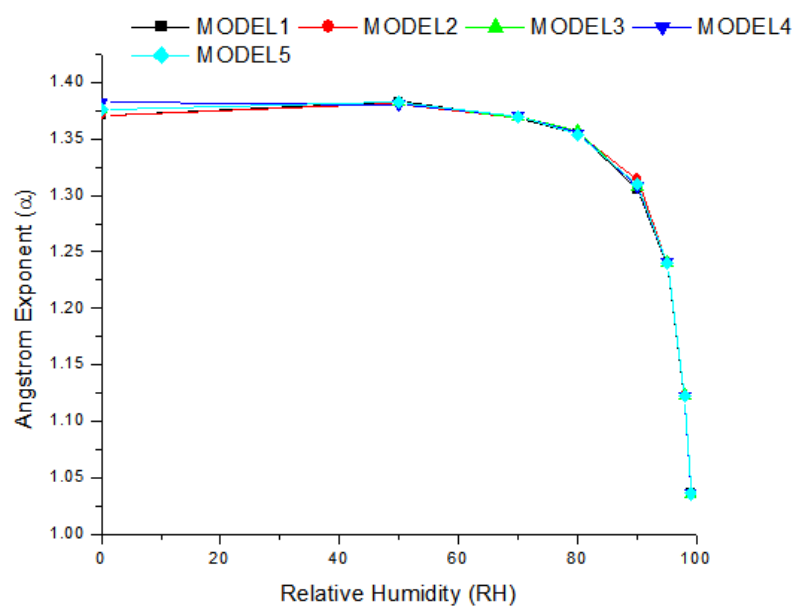

Figure 3. Graph of Angstrom Exponent $(\alpha)$ against Relative Humidity (RH) for five INSO Models

From Figure 3, for the five models, a slight difference is observed between $\alpha$ values as INSO concentration increases. This may be attributed to the dissolution of the outer soluble coating surrounding INSO aerosol particles. At $40-50 \%$ RH $\alpha$ values show constant particle size distribution. This particle size distribution decreases form 90-100\% RH indicating no hygroscopic growth.

Table 3. Visibility analysis (Model 1-INSO)

\begin{tabular}{cccc|cccc}
\hline \multicolumn{4}{c|}{ Linear } & \multicolumn{4}{c}{ Quadratic } \\
\hline $\mathrm{RH}$ & $\mathrm{R}^{2}$ & $\alpha$ & $\beta$ & $\mathrm{R}^{2}$ & $\alpha_{1}$ & $\alpha_{2}$ & $\beta$ \\
\hline $0 \%$ & 0.99894 & 1.37041 & 0.08477 & 0.99985 & 1.60567 & 0.20864 & 0.08017 \\
$50 \%$ & 0.99827 & 1.38295 & 0.11396 & 0.99985 & 1.70502 & 0.28563 & 0.10557 \\
$70 \%$ & 0.99827 & 1.36909 & 0.13380 & 0.99985 & 1.71453 & 0.30636 & 0.12327 \\
$80 \%$ & 0.99827 & 1.35505 & 0.15507 & 0.99985 & 1.68279 & 0.29066 & 0.14347 \\
$90 \%$ & 0.99749 & 1.30490 & 0.21250 & 0.99985 & 1.67672 & 0.32975 & 0.19455 \\
$95 \%$ & 0.99639 & 1.23990 & 0.30787 & 0.99985 & 1.66485 & 0.37687 & 0.27834 \\
$98 \%$ & 0.99510 & 1.12185 & 0.52262 & 0.99985 & 1.57011 & 0.39754 & 0.46988 \\
$99 \%$ & 0.99398 & 1.03662 & 0.74795 & 0.99985 & 1.49644 & 0.40780 & 0.67064 \\
\hline
\end{tabular}

From Table 3, Model 1 the $\mathrm{R}^{2}$ values for both the quadratic and linear parts show that $\mathrm{R}^{2}$ values fit the equation models well. From the linear part, the values of $\alpha$ are greater than 1 . This shows that the aerosols are fine mode particles. There is an increase in $\alpha$ value from $0-50 \%$ relative humidity and this is due to coagulation of particles at the onset of water uptake by the WASO particles present in the aerosol mixture, these particles later drop from the atmosphere when they become too heavy. $\alpha$ values decrease from $50-99 \%$ relative humidity, this implies hygroscopic growth in aerosol particles and an increase in particle size distribution. From the quadratic part, $\alpha_{2}$ is positive which indicates a bimodal distribution and dominance of fine mode particles. The Turbidity $(\beta)$ is seen to increase from $0-99 \%$ relative humidity which indicates hazy atmospheric conditions and deterioration in visibility as relative humidity increases.

The variations in $\alpha, \alpha_{2}$ and $\beta$ in Models 2, 3, 4 and 5 are similar to those of Model 1 from Table 3 as seen from Appendix B Table 1, 3, 5, and 7 respectively.

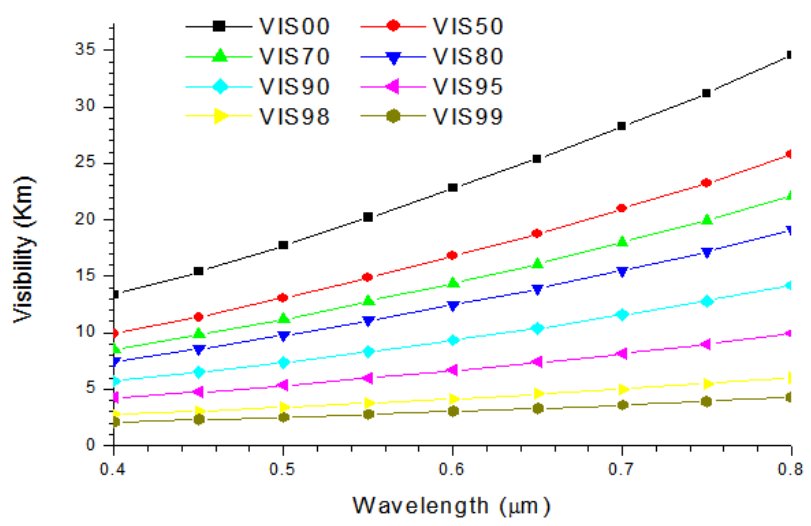

Figure 4. Visibility against Wavelength for INSO

From Figure 4, the visibility decreases with the increase in $\mathrm{RH}$ but increases with the increase in wavelength. Visibility is lower at shorter wavelength due to dominance of fine mode aerosol particles.

Table 4. Size Distribution and Hygroscopic Growth analysis (Model 1-INSO)

\begin{tabular}{cccc}
\hline & & & $\mu=5.12735$ \\
\hline$\lambda$ & $\mathrm{R}^{2}$ & $\gamma$ & $\nu$ \\
\hline 0.55 & 0.998 & 0.409 & 3.098481 \\
0.65 & 0.997 & 0.416 & 3.130541 \\
0.75 & 0.996 & 0.417 & 3.139715 \\
\hline
\end{tabular}

From Table 4 Model $1, \mathrm{R}^{2}$ values fit the equation models very well. The Visibility Enhancement $f(R H, \lambda)$ has satisfied the inverse power law. The increase in humidification factor $(\gamma)$ and the mean aerosol particle size distribution $(v)$ with wavelength implies that the number of larger particles increases compared to the number of smaller particles at longer wavelengths and smaller particles have more effect in decreasing visibility at shorter wavelengths. The values of $v>3$ imply typical hazy atmospheric conditions (Junge 1958).

The variations in the humidification factor $(\gamma)$ and the mean aerosol particle size distribution (v) of Models 2, 3, 4 and 5 are similar to those of Model 1 from Table 4 as seen in Appendix B Table 2, 4, 6 and 8 respectively.

For varying INSO aerosol concentration, the mean 
exponent hygroscopic growth curve $(\mu)$ increases with increasing INSO concentration and this implies a decrease in effective hygroscopic growth $\left(g_{e f f}\right)$.

\subsection{SOOT Particle Concentration}

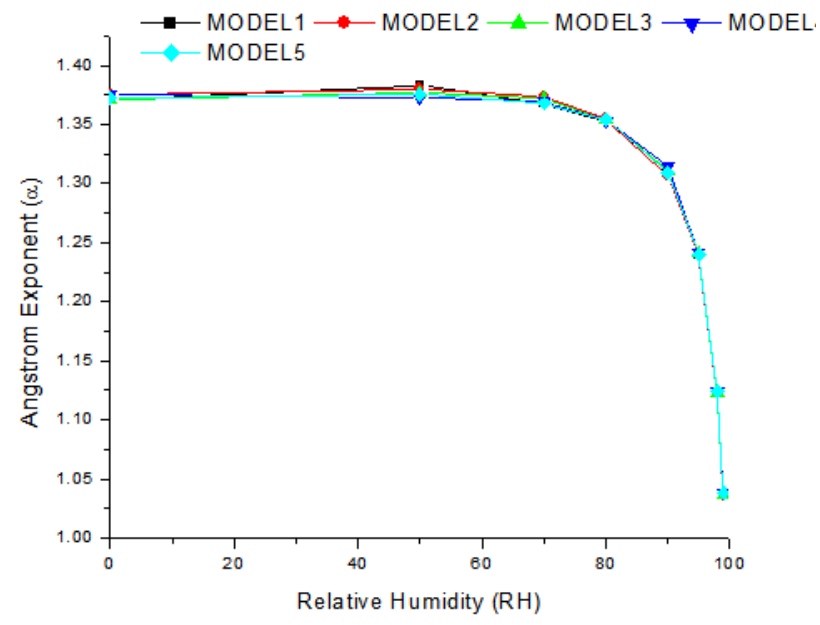

Figure 5. Graph of Angstrom Exponent ( $\alpha$ ) against Relative Humidity (RH) for five SOOT Models

From Figure 5 constant $\alpha$ values are observed for all models at $0 \% \mathrm{RH}$ as SOOT concentration increases. For each model, $\alpha$ values show an increase in particle size distribution at $50 \% \mathrm{RH}$ which may be attributed to the small percentage of insoluble aerosol concentration found within the SOOT aerosol mixture.

Table 5. Visibility analysis (Model 1-SOOT)

\begin{tabular}{cccc|cccc}
\hline \multicolumn{4}{c|}{ Linear } & \multicolumn{4}{c}{ Quadratic } \\
\hline $\mathrm{RH}$ & $\mathrm{R}^{2}$ & $\alpha$ & $\beta$ & $\mathrm{R}^{2}$ & $\alpha_{1}$ & $\alpha_{2}$ & $\beta$ \\
\hline $0 \%$ & 0.99894 & 1.37041 & 0.08477 & 0.99985 & 1.60567 & 0.20864 & 0.08017 \\
$50 \%$ & 0.99894 & 1.38349 & 0.11380 & 0.99985 & 1.67475 & 0.25831 & 0.10620 \\
$70 \%$ & 0.99791 & 1.36764 & 0.13388 & 0.99985 & 1.71819 & 0.31089 & 0.12319 \\
$80 \%$ & 0.99791 & 1.35324 & 0.15517 & 0.99985 & 1.68392 & 0.29326 & 0.14346 \\
$90 \%$ & 0.99706 & 1.31005 & 0.21144 & 0.99985 & 1.70855 & 0.35341 & 0.19237 \\
$95 \%$ & 0.99643 & 1.23999 & 0.30716 & 0.99985 & 1.66222 & 0.37446 & 0.27788 \\
$98 \%$ & 0.99516 & 1.12366 & 0.52074 & 0.99985 & 1.56992 & 0.39577 & 0.46842 \\
$99 \%$ & 0.99392 & 1.03680 & 0.74575 & 0.99985 & 1.49880 & 0.40973 & 0.66832 \\
\hline
\end{tabular}

From Table 5, Model $1 \mathrm{R}^{2}$ values fit the equation models very well. From the linear part, the values of $\alpha$ are greater than 1 . This shows that the aerosols are fine mode particles. There is an increase in $\alpha$ value from $0-50 \%$ relative humidity and this is due to coagulation of water soluble particles present in the mixture particles as they begin to absorb water. $\alpha$ values decrease from $50-99 \%$ relative humidity, this implies hygroscopic growth in aerosol particles and an increase in particle size distribution this can be attributed to the hygroscopic properties of the outer soluble coating of the insoluble core combined with the effect of some of the water soluble aerosols found within the mixture. From the quadratic part, $\alpha_{2}$ is positive which indicates a bimodal distribution and dominance of fine mode particles. The Turbidity $(\beta)$ is seen to increase from $0-99 \%$ relative humidity which indicates hazy atmospheric conditions and deterioration in visibility as relative humidity increases.

The variations in $\alpha, \alpha_{2}$ and $\beta$ in Models 2, 3, 4 and 5 are similar to those of Model 1 from Table 5 as seen from Appendix C Table 1, 3, 5, and 7 respectively.

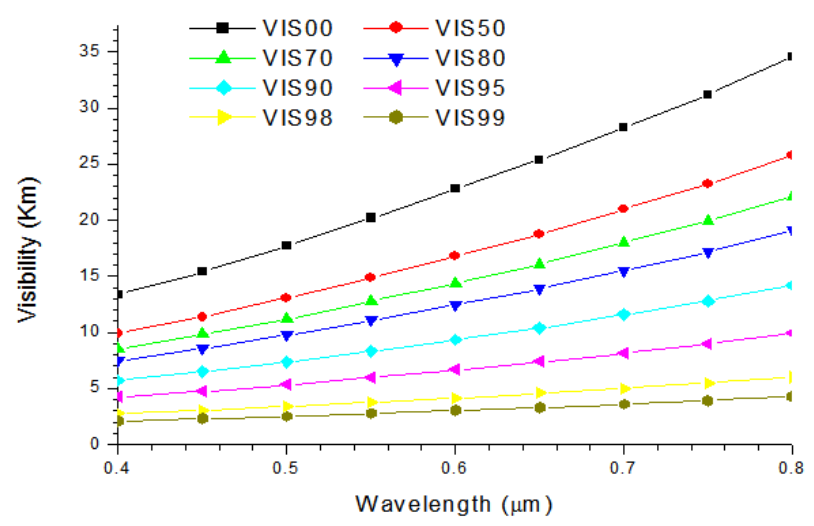

Figure 6. Visibility against Wavelength for SOOT

From Figure 6, the visibility decreases with the increase in $\mathrm{RH}$ but increases with the increase in wavelength. Visibility is lower at shorter wavelength due to dominance of soot particles.

Table 6. Size Distribution and Hygroscopic Growth analysis (Model 1-SOOT)

\begin{tabular}{cccc}
\hline & & & $\mu=5.12877$ \\
\hline$\lambda$ & $\mathrm{R}^{2}$ & $\gamma$ & $\nu$ \\
\hline 0.55 & 0.998 & 0.421 & 3.158174 \\
0.65 & 0.997 & 0.429 & 3.201624 \\
0.75 & 0.996 & 0.434 & 3.226229 \\
\hline
\end{tabular}

From Table 6 Model 1, the values of $\mathrm{R}^{2}$ show that the data fitted the equation models very well. The Visibility Enhancement $f(R H, \lambda)$ has satisfied the inverse power law. The increase in humidification factor $(\gamma)$ and the mean aerosol particle size distribution $(v)$ with wavelength implies that the number of larger particles increases compared to the number of smaller particles at longer wavelengths and smaller particles have more effect in decreasing visibility at shorter wavelengths. The values of $v>3$ imply typical hazy atmospheric conditions (Junge 1958).

The variations in the humidification factor $(\gamma)$ and the mean aerosol particle size distribution ( $v$ ) of Models 2, 3, 4 and 5 are similar to those of Model 1 from Table 6 as 
seen in Appendix C Table 2, 4, 6 and 8 respectively.

The values of the mean exponent hygroscopic growth curve $(\mu)$ increases with increasing SOOT aerosol concentration across the models and this implies a decrease in the effective hygroscopic growth $\left(g_{e f f}\right)$.

\section{Conclusions}

From the five model analyses carried out for each component (WASO, INSO and SOOT) respectively, it was concluded that $\alpha$ is greater than 1 which indicates fine mode particles. As WASO concentration increases, $\alpha$ increases and this implies an increase in fine mode particles. $\alpha_{2}$ is positive for all models. This shows that the aerosol distribution is bimodal with fine mode particles as dominant. Additionally, it was observed that as the RH and WASO concentration increases, there were fluctuations in the values of $\alpha_{2}$ and this may imply a nonlinear relationship between the externally mixed aerosols. Similarly, the above conclusions apply for varying INSO and SOOT concentrations respectively. The Turbidity $(\beta)$ was observed to increase from $0-99 \%$ relative humidity which indicated hazy atmospheric conditions and deterioration in visibility as relative humidity increased.

Visibility decreases with an increase in relative humidity and WASO, INSO and SOOT aerosol concentrations across all models respectively. As INSO and WASO aerosol concentrations and relative humidity increased, the hygroscopic or water soluble part of the aerosol mixture were found to be the main contributors in the degradation of visibility.

It was observed that across the models as $\mathrm{RH}$ increased (1-RH) decreased. With the increase in WASO concentration, $\mu$ decreased this implied that as WASO concentration increased, $1 / \mu$ increased and $g_{\text {eff }}$ increased. The Visibility enhancement decreased as RH increased. The humidification factor $(\gamma)$ decreased then later increased this maybe due to a non linear relationship between WASO concentration and Visibility enhancement. $v$ behaved as $\gamma$ thus this implies that there is also a non linear relationship between the variation in WASO concentration and the change in particle size distribution. As relative humidity increased, $g_{\text {eff }}$ increased while $\mu$ decreased and as WASO concentration increased, $g_{e f f}$ increased while $\mu$ decreased. $\gamma$ decreased and then increased.

With the increase in INSO concentration, $\mu$ increased this implied that as INSO concentration increased, $1 / \mu$ decreased and $g_{\text {eff }}$ decreased.The humidification factor $(\gamma)$ decreased and this implied that increase in INSO concentration reduced absorption of water. $v$ fluctuates, this implies that there is also a non linear relationship between the variation in INSO concentration and the change in particle size distribution. As relative humidity increased, $g_{\text {eff }}$ decreased while $\mu$ increased and as INSO concentration increased, $g_{\text {eff }}$ decreased while $\mu$ increased, $\gamma$ decreased all through.

With increasing SOOT concentration, $g_{e f f}$ decreased as $1 / \mu$ decreased and the humidification factor $(\gamma)$ decreases which implies that the increase in SOOT concentration reduced water uptake. $v$ decreases which implies a decrease in particle size distribution. As relative humidity increased, $g_{\text {eff }}$ decreased while $\mu$ increased and as SOOT concentration increased, $g_{\text {eff }}$ decreased while $\mu$ increased, $\gamma$ decreased all through.

\section{Author Contributions}

Both authors named in this work took part in data generation, analysis, result presentation and conclusions.

\section{Conflict of Interest}

All authors whose names are indicated in this write-up certify that they have no affiliations or involvement with any organization that has financial or non financial interest in the content of this research.

\section{Funding}

This research did not receive any external funding.

\section{Acknowledgements}

The authors are grateful to Prof. Usman M. Gana and Prof. Muntari Hajara Ali of the Physics Department Bayero University, Kano, Nigeria for reading this article and forwarding all necessary corrections. The OPAC 4.0 software package used to generate the data for this work is available at http//www.rascin.net/en/opac40.

\section{References}

[1] Wu, D., Li, X. X., Ying, C. C., Lau, Z. M., Huang, A. K. H., Deng, J., X. J.,\&Bi, X. Y. (2005): An extremely low visibility event over the Guangzhou region: A case study, Atmos. Environ., 39(35), 6568-6577. https://doi. org/10.1016/j.atmosenv.2005.07.061.

[2] Bret, A. S., Rudolf, B. H., Stefan. R. F, \& William E.W., (2001). Haze trends over the United States, 1980-1995. Journal of Atmosphere and Environment. 35: 5205-5210. https://doi.org/10.1016/S1352-2310 (01)00317-X.

[3] Chan, Y.C., Simpson, R.W., Mctainsh, G. H., Vowles, P. D., Cohen D. D.,\& Bailey, G. M., (1999). Source Apportionment of Visibility Degradation Problems in Brisbane (Australia) Using the Multiple Linear 
Regression Techniques. Journal of Atmosphere and Environment. 33: 3237-3250. https://doi.org/10.1016/ S1352-2310(99)00091-6.

[4] Doylem, M. \& Dorling S., (2002). Visibility Trends in the UK 1950-1997. Journal of Atmosphere and Environment. 36: 3163-3172. https://doi.org/10.1016/ S1352-2310(02)00248-0.

[5] Kotchenruther, R. A., Hobbs, P.V., Hegg, D. A., (1999). Humidification factors for atmospheric aerosol off the midAtlantic coast of United States. J. Geophys. Res. 104 (D2), 2239-2251. https://doi.org/10.1029/ 98JD01751.

[6] Yoon, S.C., Kim, J., (2006). Influences of relative humidity on aerosol optical properties and aerosol radiative forcing during ACE-Asia. Atmos. Environ. 40 (23), 4328-4338 https://doi.org/10.1016/j.atmosenv.2006.03.036.

[7] Chan, C. K., \& Yao, X. H., (2008): Air pollution in mega cities in China, Atmos. Environ., 42, 1-42. https://doi.org/10.1016/j.atmosenv.2007.09.003.

[8] Deng, X. J., Tie X. X., Wu, D., Zhou, X. J., Bi, X.Y., Tan H. B., Li F., \& Jiang C. L., (2008): Long- Term Trend of Visibility and Its Characterizations in the Pearl River Delta (PRD) Region, China. Journal of Atmosphere and Environment .42(7), 1424-1435. https:// doi.org/10.1016/j.atmosenv.2007.11.025.

[9] Massoli, P., Bates, T. S., Quinn, P.K., Lack, D.A., Baynard, T., Lerner, B.M., TuckerS.C.,,Brioude, J., Stohl, A., Williams, E.J., (2009). Aerosol optical and hygroscopic properties during TexAQS-GoMACCS 2006 and their impact on aerosol direct radiative forcing. $J$. Geophys. Res. 114, D00F07. https://doi.org/10.1029/ 2008JD011604.

[10] Tijjani B. I. (2013). The Effect of Soot and Water Soluble on the Hygroscopicity of Urban Aerosols. Advances in Physics Theories and Applications. www.iiste.org ISSN 2224-719X (Paper) ISSN 22250638, Vol.26.

[11] Cheng, Y. F., Wiedensohler A., Eichler H., Heintzenberg J., Tesche M., Ansmann A., Wendisch M., Su H.,Althausen D.,HerrmannH., Gnauk T., Bruggemann E., Hu M., Zhang Y.H., (2008). Relative Humidity Dependence of Aerosol Optical Properties and Direct Radiative Forcing in The Surface Boundary Layer at Xinken in Pearl River Delta of China: An Observation Based Numerical Study. Journal of Atmosphere and Environment. 42, 6373-6397. https:// doi.org/10.1016/j.atmosenv.2008.04.009.

[12] Koschmieder, H., (1972): Theorie der horizontalenSichtweite, BeiträgezurPhysik der freienAtmosphäre, Meteorol. Z., 12, 33-55.
[13] Liu et al. X. (2012). 'Aerosol Hygroscopicity and Its Impact on Atmospheric Visibility and Radiative Forcing in Guangzhou during the 2006 PRIDE-PRD Campaign'. Atmospheric Environment 60: 59-67. https://doi.org/10.1016/j.atmosenv.2012.06.016.

[14] Liu, X.G., Zhang, Y.H., Jung, J.S., Gu, J.W., Li, Y.P., Guo, S., Chang, S.Y., Yue, D., Lin, P., Kim, Y.J., Hu, M., Zeng, L.M.,Zhu, T., (2009). Research on aerosol hygroscopic properties by measurement and model during the 2006 CARE Beijing campaign.J. Geophys. Res. 114, D00G16.

[15] Liu, X.G., Zhang, Y.H., Wen, M.T., Wang, J.L., Jung, J.S., Chang, S.Y., Hu, M., Zeng, L.M., Kim, Y.J., (2010).A closure study of aerosol hygroscopic growth factor during the 2006 PRD campaign. $A d v$. Atmos. Sci..

[16] Reid, J.S., Jayaraman, A., Kiehl, J.T., Krishnamurti, T.N.\&Lubin, D. (1999). Physical, chemical and optical regional hazes dominated by smoke in Brazil. Journal of Geophysical Research, 103: 32059-32080. https://doi.org/10.1029/98JD00458.

[17] Sjogren, S. et al. (2007). 'Hygroscopic Growth and Water Uptake Kinetics of Two-Phase Aerosol Particles Consisting of Ammonium Sulfate, Adipic and Humic Acid Mixtures'. 38: 157-71.

[18] Tijjani, B. I. Aliyu, A. \& Shaaibu F. (2014b). 'The Effect of Relative Humidity on Continental Average Aerosols'. Open Journal of Applied Sciences, 4, 399423 (6) 10.4236/ojapps.2014.47038.

[19] King, M.\& Byrne, D. (1976). A method for inferring total ozone content from the spectral variation of total optical depth obtained with a solar radiometer. Journal of Geophysical Research, 33: 3251-3254. https://doi.org/10.1175/1520-0469(1976)033<2242 :AMFITO $>2.0 . \mathrm{CO} ; 2$.

[20] Yuan, C. S., Lee, C. G, Chang J. C. \& Yuan C. (2005) Effects of Aerosol Species on Atmospheric Visibility in Kaohsiung City, Taiwan. Journal of Air \& Waste Management Association.55:1031-1041 https://doi.or $\mathrm{g} / 10.1080 / 10473289.2005 .10464683$.

[21] Kim, Jiyoung, Soon-chang Yoon, Anne Jefferson, and Sang-woo Kim. (2006). 'Aerosol Hygroscopic Properties during Asian Dust, Pollution, and Biomass Burning Episodes at Gosan, Korea in April 2001. Atmos. Environ., 40, 1550-1560.

[22] Ångström A. (1961). Techniques of Determining the Turbidity. Tellus, 13(2): 214-223. https://doi. org/10.3402/tellusa.v13i2.9493.

[23] Galadanci, G.S.M., Tijjani, B.I., Abubakar, A.I., Koki, F. S., Adamu, I. D., Nura, A. M., Saleh, M.,\&Uba, S. (2015): The Effect of Kelvin Effect On 
The Equilibrium Effective Radii And Hygroscopic Growth of Atmospheric Aerosols. IISTE- Journal of Natural Sciences Research, Vol.5, No.22, 2015 p96-111. https://core.ac.uk/download/pdf/ 234656185.pdf.

[24] Kasten F. (1969). Visibility forecast in the phase of pre-condensation. Tellus, XXI, 5, 631-635. https://doi.org/10.1111/j.2153-3490.1969.tb00469.x.

[25] Kaufman Y. (1993). Aerosol optical thickness and path radiance.Journal of Geophysical research 98 (D2) 2677-2692. https://doi.org/10.1029/ 92JD02427.

[26] Tang, I.N., Munkelwitz, H.R., (1994). Water activities, densities, and refractive indices of aqueous sulfate and sodium nitrate droplets of atmospheric importance.J. Geophys. Res. 99 (D9), 18,801-18,808. https://doi.org/10.1029/94JD01345.

[27] Tijjani, B. I., Sha'aibu F.\&Aliyu. A. (2014a).The Effect of Relative Humidity on Maritime Polluted Aerosols.International Journal of Pure and Applied Physics Vol.2, No.1, Pp.9-36.

[28] Eck, T. F., Holben, B. N., Ward,D. E., Dubovic, R. J. S., Smirnov, A., Mukelabai M. M., Hsu, N. C., O' Neil N. T.,\&Slutsker I. (2001) Characterization of The Optical Properties of Biomass Burning Aerosols in Zambia During the 1997 ZIBBEE Field Campaign, Journal of Geophysics Research, 106(D4), 3425-3448. https://doi.org/10.1029/2000JD900555.

[29] Moln'ar, A., M'esz'aros, E., Imre, K., \&R"ull, A. (2008): Trends in visibility over Hungary between 1996 and 2002, Atmos. Environ., 42, 2621-2629. https://doi.org/10.1016/j.atmosenv.2007.05.012.
[30] Frankenberger, E. (1967) Beitr. Phys. Atmos. 37, 183.

[31] Zieger, P., Fierz-Schmidhauser,R., Poulain, L., Müller, T., Birmili, W., Spindler, G., Wiedensohler, A.,Baltensperger, U., \&Weingartner, E. (2013): Effects of relative humidity on aerosol light scattering: results from different European sites, Atmos. Chem. Phys., 13, 10609-10631. https://doi.org/10.5194/acp13-10609-2013.

[32] Quinn, P. K.,et al. (2005), Impact of particulate organic matter on the relative humidity dependence of light scattering: A simplified parameterization, Geophys. Res. Lett., 32, L22809,. https://doi. org/10.1029/2005GL024322.

[33] Junge, C. E. (1958). Atmospheric Chemistry. Advances in geophysics (Vol. 4, pp 1-108). Elsevier. https://doi.org/10.1016/S0065-2687(08)60484-7.

[34] TangI. N. (1996).Chemical and size effects of hygroscopic aerosols on light scattering coefficients. Journal of Geophysical Research 101 (D14), 19,24519,250 https://doi.org/10.1029/96JD03003.

[35] Hess, M., Koepke, P., and Schult, I. (1998): Optical properties of aerosols and clouds: The software package OPAC, B. Am. Meteor. Soc., 79, 831-844.

\section{Appendix A}

\section{Water-Soluble (WASO)}

Table 1. Visibility analysis (Model 2- WASO)

\begin{tabular}{cccc|cccc}
\hline & \multicolumn{3}{c}{ Linear } & \multicolumn{3}{c}{ Quadratic } \\
\hline $\mathrm{RH}$ & $\mathrm{R}^{2}$ & $\alpha$ & $\beta$ & $\mathrm{R}^{2}$ & $\alpha_{1}$ & $\alpha_{2}$ & $\beta$ \\
\hline $0 \%$ & 0.99906 & 1.35151 & 0.08688 & 0.99974 & 1.55343 & 0.17907 & 0.08282 \\
$50 \%$ & 0.99906 & 1.36385 & 0.11608 & 0.99974 & 1.61834 & 0.22570 & 0.10928 \\
$70 \%$ & 0.99793 & 1.35748 & 0.13548 & 0.99974 & 1.70018 & 0.30393 & 0.12490 \\
$80 \%$ & 0.99793 & 1.34193 & 0.15736 & 0.99974 & 1.69715 & 0.31504 & 0.14464 \\
$90 \%$ & 0.99722 & 1.30589 & 0.21267 & 0.99974 & 1.69886 & 0.34851 & 0.19373 \\
$95 \%$ & 0.99649 & 1.23363 & 0.30933 & 0.99974 & 1.65025 & 0.36949 & 0.28021 \\
$98 \%$ & 0.99516 & 1.11938 & 0.52310 & 0.99974 & 1.56387 & 0.39420 & 0.47074 \\
$99 \%$ & 0.99392 & 1.03360 & 0.74808 & 0.99974 & 1.49403 & 0.40834 & 0.67065 \\
\hline
\end{tabular}


Table 2. Size Distribution and Hygroscopic Growth analysis (Model 2-WASO)

\begin{tabular}{cccc}
\hline & & & $\mu=5.12299$ \\
\hline$\lambda$ & $\mathrm{R}^{2}$ & $\gamma$ & $\nu$ \\
\hline 0.55 & 0.998 & 0.416 & 3.13200 \\
0.65 & 0.997 & 0.424 & 3.17235 \\
0.75 & 0.996 & 0.427 & 3.19177 \\
\hline
\end{tabular}

Table 3. Visibility analysis (Model 3- WASO)

\begin{tabular}{cccc|cccc}
\hline & \multicolumn{3}{c}{ Linear } & \multicolumn{3}{c}{ Quadratic } \\
\hline $\mathrm{RH}$ & $\mathrm{R}^{2}$ & $\alpha$ & $\beta$ & $\mathrm{R}^{2}$ & $\alpha_{1}$ & $\alpha_{2}$ & 0.08502 \\
\hline $0 \%$ & 0.99942 & 1.33858 & 0.08836 & 0.99987 & 1.50106 & 0.14410 & 0.11000 \\
$50 \%$ & 0.99847 & 1.35279 & 0.11773 & 0.99987 & 1.63925 & 0.25405 & 0.12731 \\
$70 \%$ & 0.99847 & 1.34792 & 0.13705 & 0.99987 & 1.65862 & 0.27555 & 0.14827 \\
$80 \%$ & 0.99847 & 1.33113 & 0.15898 & 0.99987 & 1.62521 & 0.26081 & 0.19725 \\
$90 \%$ & 0.99747 & 1.29306 & 0.21535 & 0.99987 & 1.66314 & 0.32821 & 0.28153 \\
$95 \%$ & 0.99646 & 1.23035 & 0.31083 & 0.99987 & 1.64759 & 0.37003 & 0.47245 \\
$98 \%$ & 0.99519 & 1.11688 & 0.52472 & 0.99987 & 1.55909 & 0.39218 & 0.40257 \\
$99 \%$ & 0.99408 & 1.03238 & 0.74970 & 0.99987 & 1.48631 & 0.47314 \\
\hline
\end{tabular}

Table 4. Size Distribution and Hygroscopic Growth analysis (Model 3-WASO)

\begin{tabular}{cccc}
\hline & & & $\mu=5.12079$ \\
\hline$\lambda$ & $\mathrm{R}^{2}$ & $\gamma$ & $\nu$ \\
\hline 0.55 & 0.998 & 0.414 & 3.121978 \\
0.65 & 0.997 & 0.421 & 3.160147 \\
0.75 & 0.996 & 0.425 & 3.177426 \\
\hline
\end{tabular}

Table 5. Visibility analysis (Model 4- WASO)

\begin{tabular}{cccc|cccc}
\hline & \multicolumn{3}{c|}{ Linear } & \multicolumn{3}{c}{ Quadratic } \\
\hline $\mathrm{RH}$ & $\mathrm{R}^{2}$ & $\alpha$ & $\beta$ & $\mathrm{R}^{2}$ & $\alpha_{1}$ & $\alpha_{2}$ & $\beta$ \\
\hline $0 \%$ & 0.99900 & 1.32447 & 0.08993 & 0.99965 & 1.51808 & 0.17170 & 0.08589 \\
$50 \%$ & 0.99850 & 1.34896 & 0.11883 & 0.99965 & 1.63267 & 0.25161 & 0.11109 \\
$70 \%$ & 0.99850 & 1.34027 & 0.13852 & 0.99965 & 1.65464 & 0.27880 & 0.12856 \\
$80 \%$ & 0.99850 & 1.32827 & 0.16036 & 0.99965 & 1.68449 & 0.31592 & 0.14736 \\
$90 \%$ & 0.99728 & 1.29296 & 0.21611 & 0.99965 & 1.66853 & 0.33308 & 0.19768 \\
$95 \%$ & 0.99728 & 1.22767 & 0.31207 & 0.99965 & 1.63779 & 0.36371 & 0.28313 \\
$98 \%$ & 0.99539 & 1.11634 & 0.52579 & 0.99965 & 1.54599 & 0.38104 & 0.47483 \\
$99 \%$ & 0.99373 & 1.03402 & 0.75093 & 0.99965 & 1.50203 & 0.41506 & 0.67200 \\
\hline
\end{tabular}

Table 6. Size Distribution and Hygroscopic Growth analysis (Model 4-WASO)

\begin{tabular}{cccc}
\hline & & & $\mu=5.11871$ \\
\hline$\lambda$ & $\mathrm{R}^{2}$ & $\gamma$ & $\nu$ \\
\hline 0.55 & 0.998 & 0.412 & 3.11302 \\
0.65 & 0.997 & 0.419 & 3.148495 \\
0.75 & 0.996 & 0.422 & 3.161708 \\
\hline
\end{tabular}


Table 7. Visibility analysis (Model 5- WASO)

\begin{tabular}{cccccccc}
\hline & \multicolumn{3}{c}{ Linear } & \multicolumn{5}{c}{ Quadratic } \\
\hline $\mathrm{RH}$ & $\mathrm{R}^{2}$ & $\alpha$ & $\beta$ & $\mathrm{R}^{2}$ & $\alpha_{1}$ & $\alpha_{2}$ & $\beta$ \\
\hline $0 \%$ & 0.99939 & 1.31346 & 0.09157 & 0.99982 & 1.46925 & 0.13816 & 0.08825 \\
$50 \%$ & 0.99939 & 1.32863 & 0.12111 & 0.99982 & 1.57453 & 0.21808 & 0.11424 \\
$70 \%$ & 0.99829 & 1.33482 & 0.13964 & 0.99982 & 1.63901 & 0.26977 & 0.12991 \\
$80 \%$ & 0.99829 & 1.32433 & 0.16122 & 0.99982 & 1.65024 & 0.28904 & 0.14922 \\
$90 \%$ & 0.99742 & 1.28527 & 0.21799 & 0.99982 & 1.65620 & 0.32897 & 0.19962 \\
$95 \%$ & 0.99742 & 1.22247 & 0.31398 & 0.99982 & 1.62767 & 0.35936 & 0.28519 \\
$98 \%$ & 0.99518 & 1.11222 & 0.52816 & 0.99982 & 1.55306 & 0.39096 & 0.47570 \\
$99 \%$ & 0.99396 & 1.02970 & 0.75276 & 0.99982 & 1.48734 & 0.40587 & 0.67530 \\
\hline
\end{tabular}

Table 8. Size Distribution and Hygroscopic Growth analysis (Model 5-WASO)

\begin{tabular}{cccc}
\hline & & & $\mu=5.11657$ \\
\hline$\lambda$ & $\mathrm{R}^{2}$ & $\gamma$ & $\nu$ \\
\hline 0.55 & 0.998 & 0.410 & 3.10370 \\
0.65 & 0.997 & 0.416 & 3.130541 \\
0.75 & 0.996 & 0.419 & 3.147515 \\
\hline
\end{tabular}

\section{Appendix B}

\section{Insoluble (INSO)}

Table 1. Visibility analysis (Model 2- INSO)

\begin{tabular}{cccccccc}
\hline & \multicolumn{3}{c}{ Linear } & \multicolumn{5}{c}{ Quadratic } \\
\hline $\mathrm{RH}$ & $\mathrm{R}^{2}$ & $\alpha$ & $\beta$ & $\mathrm{R}^{2}$ & $\alpha_{1}$ & $\alpha_{2}$ & $\beta$ \\
\hline $0 \%$ & 0.99902 & 1.37058 & 0.08533 & 0.99985 & 1.59501 & 0.19904 & 0.08091 \\
$50 \%$ & 0.99842 & 1.38126 & 0.11463 & 0.99985 & 1.68550 & 0.26982 & 0.10665 \\
$70 \%$ & 0.99871 & 1.36932 & 0.13408 & 0.99985 & 1.64651 & 0.24583 & 0.12555 \\
$80 \%$ & 0.99751 & 1.35485 & 0.15626 & 0.99985 & 1.73701 & 0.33893 & 0.14272 \\
$90 \%$ & 0.99712 & 1.31448 & 0.21223 & 0.99985 & 1.71683 & 0.35683 & 0.19291 \\
$95 \%$ & 0.99635 & 1.24052 & 0.30969 & 0.99985 & 1.66775 & 0.37889 & 0.27983 \\
$98 \%$ & 0.99518 & 1.12282 & 0.52574 & 0.99985 & 1.56806 & 0.39487 & 0.47302 \\
$99 \%$ & 0.99388 & 1.03637 & 0.75302 & 0.99985 & 1.49985 & 0.41104 & 0.67460 \\
\hline
\end{tabular}

Table 2. Size Distribution and Hygroscopic Growth analysis (Model 2-INSO)

\begin{tabular}{cccc}
\hline & & & $\mu=5.15606$ \\
\hline$\lambda$ & $\mathrm{R}^{2}$ & $\gamma$ & $v$ \\
\hline 0.55 & 0.998 & 0.418 & 3.144787 \\
0.65 & 0.997 & 0.427 & 3.189630 \\
0.75 & 0.996 & 0.431 & 3.211264 \\
\hline
\end{tabular}


Table 3. Visibility analysis (Model 3- INSO)

\begin{tabular}{cccc|cccc}
\hline & \multicolumn{3}{c}{ Linear } & \multicolumn{5}{c}{ Quadratic } \\
\hline $\mathrm{RH}$ & $\mathrm{R}^{2}$ & $\alpha$ & $\beta$ & $\mathrm{R}^{2}$ & $\alpha_{1}$ & $\alpha_{2}$ & $\beta$ \\
\hline $0 \%$ & 0.99894 & 1.37596 & 0.08528 & 0.99996 & 1.62793 & 0.22346 & 0.08033 \\
$50 \%$ & 0.99847 & 1.38263 & 0.11498 & 0.99996 & 1.67868 & 0.26255 & 0.10718 \\
$70 \%$ & 0.99847 & 1.36909 & 0.13515 & 0.99996 & 1.71453 & 0.30636 & 0.12451 \\
$80 \%$ & 0.99847 & 1.35685 & 0.15653 & 0.99996 & 1.68166 & 0.28806 & 0.14492 \\
$90 \%$ & 0.99743 & 1.30791 & 0.21453 & 0.99996 & 1.68537 & 0.33475 & 0.19615 \\
$95 \%$ & 0.99638 & 1.24005 & 0.31167 & 0.99996 & 1.66513 & 0.37699 & 0.28177 \\
$98 \%$ & 0.99520 & 1.12275 & 0.52927 & 0.99996 & 1.56688 & 0.39388 & 0.47633 \\
$99 \%$ & 0.99387 & 1.03626 & 0.75816 & 0.99996 & 1.49990 & 0.41118 & 0.67917 \\
\hline
\end{tabular}

Table 4. Size Distribution and Hygroscopic Growth analysis (Model 3-INSO)

\begin{tabular}{cccc}
\hline & & & $\mu=5.18455$ \\
\hline$\lambda$ & $\mathrm{R}^{2}$ & $\gamma$ & $\nu$ \\
\hline 0.55 & 0.998 & 0.419 & 3.150005 \\
0.65 & 0.997 & 0.427 & 3.191274 \\
0.75 & 0.996 & 0.432 & 3.216909 \\
\hline
\end{tabular}

Table 5. Visibility analysis (Model 4- INSO)

\begin{tabular}{cccc|cccc}
\hline & \multicolumn{3}{c}{ Linear } & \multicolumn{5}{c}{ Quadratic } \\
\hline $\mathrm{RH}$ & $\mathrm{R}^{2}$ & $\alpha$ & $\beta$ & $\mathrm{R}^{2}$ & $\alpha_{1}$ & $\alpha_{2}$ & $\beta$ \\
\hline $0 \%$ & 0.99908 & 1.38252 & 0.08526 & 0.99978 & 1.59173 & 0.18554 & 0.08113 \\
$50 \%$ & 0.99836 & 1.38041 & 0.11583 & 0.99978 & 1.68943 & 0.27406 & 0.10764 \\
$70 \%$ & 0.99871 & 1.36991 & 0.13540 & 0.99978 & 1.64678 & 0.24554 & 0.12679 \\
$80 \%$ & 0.99748 & 1.35520 & 0.15782 & 0.99978 & 1.73955 & 0.34086 & 0.14406 \\
$90 \%$ & 0.99748 & 1.30839 & 0.21576 & 0.99978 & 1.70144 & 0.34858 & 0.19655 \\
$95 \%$ & 0.99635 & 1.24049 & 0.31351 & 0.99978 & 1.66727 & 0.37849 & 0.28332 \\
$98 \%$ & 0.99513 & 1.12283 & 0.53251 & 0.99978 & 1.57072 & 0.39722 & 0.47882 \\
$99 \%$ & 0.99392 & 1.03570 & 0.76325 & 0.99978 & 1.49707 & 0.40917 & 0.68410 \\
\hline
\end{tabular}

Table 6. Size Distribution and Hygroscopic Growth analysis (Model 4-INSO)

\begin{tabular}{cccc}
\hline & & & $\mu=5.21256$ \\
\hline$\lambda$ & $\mathrm{R}^{2}$ & $\gamma$ & $\nu$ \\
\hline 0.55 & 0.998 & 0.420 & 3.153959 \\
0.65 & 0.997 & 0.428 & 3.196834 \\
0.75 & 0.997 & 0.433 & 3.220585 \\
\hline
\end{tabular}


Table 7. Visibility analysis (Model 5- INSO)

\begin{tabular}{cccc|cccc}
\hline & \multicolumn{3}{c|}{ Linear } & \multicolumn{3}{c}{ Quadratic } \\
\hline $\mathrm{RH}$ & $\mathrm{R}^{2}$ & $\alpha$ & $\beta$ & $\mathrm{R}^{2}$ & $\alpha_{1}$ & $\alpha_{2}$ & $\beta$ \\
\hline $0 \%$ & 0.99894 & 1.37596 & 0.08613 & 0.99996 & 1.62793 & 0.22346 & 0.08114 \\
$50 \%$ & 0.99847 & 1.38263 & 0.11614 & 0.99996 & 1.67868 & 0.26255 & 0.10826 \\
$70 \%$ & 0.99847 & 1.36968 & 0.13648 & 0.99996 & 1.71480 & 0.30607 & 0.12575 \\
$80 \%$ & 0.99847 & 1.35406 & 0.15855 & 0.99996 & 1.68115 & 0.29008 & 0.14671 \\
$90 \%$ & 0.99730 & 1.30987 & 0.21665 & 0.99996 & 1.69804 & 0.34425 & 0.19758 \\
$95 \%$ & 0.99640 & 1.24022 & 0.31541 & 0.99996 & 1.66435 & 0.37614 & 0.28521 \\
$98 \%$ & 0.99499 & 1.12263 & 0.53612 & 0.99996 & 1.57614 & 0.40220 & 0.48142 \\
$99 \%$ & 0.99390 & 1.03612 & 0.76813 & 0.99996 & 1.49871 & 0.41025 & 0.68828 \\
\hline
\end{tabular}

Table 8. Size Distribution and Hygroscopic Growth analysis (Model 5-INSO)

\begin{tabular}{cccc}
\hline & & & $\mu=5.24028$ \\
\hline$\lambda$ & $\mathrm{R}^{2}$ & $\gamma$ & $\nu$ \\
\hline 0.55 & 0.998 & 0.420 & 3.155501 \\
0.65 & 0.997 & 0.429 & 3.200019 \\
0.75 & 0.997 & 0.433 & 3.222553 \\
\hline
\end{tabular}

\section{Appendix C}

\section{SOOT}

Table 1. Visibility analysis (Model 2- SOOT)

\begin{tabular}{cccc|cccc}
\hline & \multicolumn{3}{c}{ Linear } & \multicolumn{5}{c}{ Quadratic } \\
\hline $\mathrm{RH}$ & $\mathrm{R}^{2}$ & $\alpha$ & $\beta$ & $\mathrm{R}^{2}$ & $\alpha_{1}$ & $\alpha_{2}$ & $\beta$ \\
\hline $0 \%$ & 0.99894 & 1.37596 & 0.08528 & 0.99996 & 1.62793 & 0.22346 & 0.08033 \\
$50 \%$ & 0.99836 & 1.38041 & 0.11467 & 0.99996 & 1.68943 & 0.27406 & 0.10657 \\
$70 \%$ & 0.99836 & 1.37343 & 0.13358 & 0.99996 & 1.70354 & 0.29277 & 0.12352 \\
$80 \%$ & 0.99836 & 1.35501 & 0.15537 & 0.99996 & 1.68395 & 0.29173 & 0.14370 \\
$90 \%$ & 0.99836 & 1.30612 & 0.21243 & 0.99996 & 1.67494 & 0.32709 & 0.19463 \\
$95 \%$ & 0.99646 & 1.24013 & 0.30772 & 0.99996 & 1.66073 & 0.37301 & 0.27849 \\
$98 \%$ & 0.99514 & 1.12342 & 0.52133 & 0.99996 & 1.57068 & 0.39666 & 0.46883 \\
$99 \%$ & 0.99397 & 1.03585 & 0.74650 & 0.99996 & 1.49549 & 0.40764 & 0.66936 \\
\hline
\end{tabular}

Table 2. Size Distribution and Hygroscopic Growth analysis (Model 2-SOOT)

\begin{tabular}{cccc}
\hline & & & $\mu=5.13031$ \\
\hline$\lambda$ & $\mathrm{R}^{2}$ & $\gamma$ & $v$ \\
\hline 0.55 & 0.998 & 0.416 & 3.135338 \\
0.65 & 0.997 & 0.425 & 3.178341 \\
0.75 & 0.996 & 0.429 & 3.198118 \\
\hline
\end{tabular}


Journal of Atmospheric Science Research | Volume 04 | Issue 03 | July 2021

Table 3. Visibility analysis (Model 3- SOOT)

\begin{tabular}{|c|c|c|c|c|c|c|c|}
\hline \multirow[b]{2}{*}{$\mathrm{RH}$} & \multicolumn{3}{|c|}{ Linear } & \multicolumn{4}{|c|}{ Quadratic } \\
\hline & $\mathrm{R}^{2}$ & $\alpha$ & $\beta$ & $\mathrm{R}^{2}$ & $\alpha_{1}$ & $\alpha_{2}$ & $\beta$ \\
\hline $0 \%$ & 0.99937 & 1.37151 & 0.08596 & 0.99985 & 1.54290 & 0.15200 & 0.08253 \\
\hline $50 \%$ & 0.99937 & 1.37682 & 0.11507 & 0.99985 & 1.62401 & 0.21922 & 0.10852 \\
\hline $80 \%$ & 0.99811 & 1.35425 & 0.15630 & 0.99985 & 1.73675 & 0.33922 & 0.14273 \\
\hline $90 \%$ & 0.99737 & 1.31072 & 0.21228 & 0.99985 & 1.69411 & 0.34001 & 0.19382 \\
\hline $95 \%$ & 0.99644 & 1.24092 & 0.30806 & 0.99985 & 1.66315 & 0.37446 & 0.27869 \\
\hline $98 \%$ & 0.99515 & 1.12343 & 0.52184 & 0.99985 & 1.57038 & 0.39638 & 0.46933 \\
\hline $99 \%$ & 0.99408 & 1.03748 & 0.74654 & 0.99985 & 1.49361 & 0.40453 & 0.66996 \\
\hline
\end{tabular}

Table 4. Size Distribution and Hygroscopic Growth analysis (Model 3-SOOT)

\begin{tabular}{cccc}
\hline & & & $\mu=5.13170$ \\
\hline$\lambda$ & $\mathrm{R}^{2}$ & $\gamma$ & $\nu$ \\
\hline 0.55 & 0.998 & 0.415 & 3.125654 \\
0.65 & 0.997 & 0.424 & 3.172354 \\
0.75 & 0.996 & 0.428 & 3.195594 \\
\hline
\end{tabular}

Table 5. Visibility analysis (Model 4- SOOT)

\begin{tabular}{|c|c|c|c|c|c|c|c|}
\hline \multirow[b]{2}{*}{$\mathrm{RH}$} & \multicolumn{3}{|c|}{ Linear } & \multicolumn{4}{|c|}{ Quadratic } \\
\hline & $\mathrm{R}^{2}$ & $\alpha$ & $\beta$ & $\mathrm{R}^{2}$ & $\alpha_{1}$ & $\alpha_{2}$ & $\beta$ \\
\hline $0 \%$ & 0.99894 & 1.37596 & 0.08613 & 0.99996 & 1.62793 & 0.22346 & 0.08114 \\
\hline $50 \%$ & 0.99823 & 1.37277 & 0.11614 & 0.99996 & 1.69462 & 0.28544 & 0.10760 \\
\hline $80 \%$ & 0.99823 & 1.35324 & 0.15673 & 0.99996 & 1.68392 & 0.29326 & 0.14490 \\
\hline $90 \%$ & 0.99724 & 1.31463 & 0.21215 & 0.99996 & 1.70860 & 0.34939 & 0.19321 \\
\hline $95 \%$ & 0.99648 & 1.24101 & 0.30859 & 0.99996 & 1.66052 & 0.37205 & 0.27935 \\
\hline $98 \%$ & 0.99521 & 1.12462 & 0.52215 & 0.99996 & 1.56895 & 0.39406 & 0.46990 \\
\hline $99 \%$ & 0.99410 & 1.03813 & 0.74689 & 0.99996 & 1.49388 & 0.40419 & 0.67033 \\
\hline
\end{tabular}

Table 6. Size Distribution and Hygroscopic Growth analysis (Model 4-SOOT)

\begin{tabular}{cccc}
\hline & & & $\mu=5.13321$ \\
\hline 0.55 & $\mathrm{R}^{2}$ & $\gamma$ & $v$ \\
0.65 & 0.998 & 0.414 & 3.122768 \\
0.75 & 0.997 & 0.422 & 3.163033 \\
\hline
\end{tabular}


Journal of Atmospheric Science Research | Volume 04 | Issue 03 | July 2021

Table 7. Visibility analysis (Model 5- SOOT)

\begin{tabular}{|c|c|c|c|c|c|c|c|}
\hline \multirow[b]{2}{*}{$\mathrm{RH}$} & \multicolumn{3}{|c|}{ Linear } & \multicolumn{4}{|c|}{ Quadratic } \\
\hline & $\mathrm{R}^{2}$ & $\alpha$ & $\beta$ & $\mathrm{R}^{2}$ & $\alpha_{1}$ & $\alpha_{2}$ & $\beta$ \\
\hline $0 \%$ & 0.99917 & 1.37292 & 0.08685 & 0.99985 & 1.57617 & 0.18025 & 0.08276 \\
\hline $50 \%$ & 0.99917 & 1.37596 & 0.11627 & 0.99985 & 1.62793 & 0.22346 & 0.10952 \\
\hline $70 \%$ & 0.99917 & 1.36787 & 0.13551 & 0.99985 & 1.65017 & 0.25036 & 0.12673 \\
\hline $80 \%$ & 0.99812 & 1.35465 & 0.15694 & 0.99985 & 1.68142 & 0.28979 & 0.14523 \\
\hline $90 \%$ & 0.99712 & 1.30915 & 0.21360 & 0.99985 & 1.70272 & 0.34904 & 0.19455 \\
\hline $95 \%$ & 0.99649 & 1.24048 & 0.30922 & 0.99985 & 1.65916 & 0.37131 & 0.27997 \\
\hline $99 \%$ & 0.99404 & 1.03795 & 0.74757 & 0.99985 & 1.49576 & 0.40601 & 0.67061 \\
\hline
\end{tabular}

Table 8. Size Distribution and Hygroscopic Growth analysis (Model 5-SOOT)

\begin{tabular}{cccc}
\hline & & & $\mu=5.13466$ \\
\hline$\lambda$ & $\mathrm{R}^{2}$ & $\gamma$ & $\nu$ \\
\hline 0.55 & 0.998 & 0.413 & 3.116334 \\
0.65 & 0.997 & 0.421 & 3.156321 \\
0.75 & 0.996 & 0.426 & 3.182447 \\
\hline
\end{tabular}

